\title{
Introduction: objectivity in science
}

\author{
Matteo Colombo' ${ }^{1}$ Raoul Gervais ${ }^{2}$. \\ Jan Sprenger ${ }^{1}$ (D)
}

Received: 2 May 2017 / Accepted: 26 September 2017 / Published online: 24 October 2017

(C) The Author(s) 2017. This article is an open access publication

Keywords Objectivity $\cdot$ Science $\cdot$ Relativism $\cdot$ Intersubjectivity $\cdot$ Measurement

Objectivity is a buzz word in philosophy of science: it permeates various metaphysical and epistemological discussions, and it helps to build public trust in science. The epistemic authority of science seems to depend on the degree to which science is objective. Conversely, "just subjective" or "not objectively verified" are labels that are often used by science skeptics and deniers to dismiss the scientific state of the art in a discipline (e.g., climate science). Understanding scientific objectivity is crucial for making sense of the debate about the reliability of scientific research.

Central philosophical questions about objectivity in science are: What makes a scientific claim objective? Can the ideal of objectivity be attained at all? Should we even strive for it? And so on. Today, most philosophers see objectivity as a multi-faceted concept that can apply to scientific entities (theories, functions, measurements) as well as to individual reasoning processes and the social aspects of knowledge production.

All these questions were discussed at the 8th Munich-Sydney-Tilburg (MuST) conference in Tilburg, 10-12 June 2015. The papers in this special issue were presented at the conference and selected for publication through a standard double-blind peerreview process. They approach the topic of scientific objectivity from various angles: the relation to pluralism and relativism, natural laws, epistemic communities, and problems of the special sciences.

Max Bialek defends David Lewis' best system analysis of natural laws against the objection that it cannot make sense of the intuition that natural laws are objective. After

\footnotetext{
$凶 \quad$ Jan Sprenger

j.sprenger@tilburguniversity.edu

1 Tilburg Center for Logic, Ethics and Philosophy of Science (TiLPS), Tilburg University, PO Box 90153, 5037 LE Tilburg, The Netherlands

2 Grote Kauwenberg 18, S.D. 418, 2000 Antwerpen, Belgium
} 
all, what counts as "best" depends on how a scientist measures and trades off criteria such as simplicity and goodness-of-fit. There may be more than one set of natural laws. Bialek shows that one need not adopt extreme positions about the relativity of the best system analysis in order to answer this criticism.

Jaana Elgi discusses how philosophical proposals about the social organization of science should reflect the increasing democratization of science. She studies the professional ethics of American archaelogy as an example where politically motivated and epistemically motivated changes converge in practice.

Inkeri Koskinen investigates how social accounts of objectivity need to be changed in the light of the democratization of scientific inquiry, in particular in situations where one cannot readily identify the relevant epistemic community. She combines her critique of prevalent accounts of objectivity with a case study where indigenous communities are involved in the process of knowledge production.

Martin Kusch discusses the philosophical implications of a particular form of epistemic relativism: namely the idea that it is impossible to show in a non-questionbegging way that one epistemic system is superior to (all) others. Particular attention is paid to the "Problem of the Criterion": the view that the attempt to justify particular standards as objective runs into a regress problem.

David Ludwig conducts a case study about local knowledge in indigenous communities, using it as a means of evaluating the current debate about scientific objectivity. He concludes, contrary to common wisdom, that local knowledge (as opposed to universal knowledge) can often qualify as objective.

Femke Truijens tackles the view that differences between pre- and post-treatment symptom levels in medicine offer a procedurally objective quantification of treatment efficacy. She uses psychotherapy as a case to argue that this method operates on a problematic numerical basis, due to the difficulties to measure symptom levels in an objective way.

Finally, Marcel Weber engages with Searle's thesis that biological functions cannot be objective, due to their dependency on the goals that we value (e.g., life and survival). Against Searle, Weber argues that functions do not ontologically depend on values and that function statements are made true by supposedly objective features such as causal dependence, part-whole relations, or mechanistic constitution.

We would like to thank the authors and referees for their excellent work, and the conference participants for what has been a highly stimulating, inspiring and pleasurable meeting. We are also indebted to the funding agencies who supported the conference and the making of this special issue (NWO Vidi Project 276-20-023 and ERC Starting Investigator Grant 640638). Finally, our thanks go to Gila Sher, editorin-chief at Synthese, for giving us the opportunity to produce this special issue, and for accompanying and guiding us, the guest editors, during the process.

Open Access This article is distributed under the terms of the Creative Commons Attribution 4.0 International License (http://creativecommons.org/licenses/by/4.0/), which permits unrestricted use, distribution, and reproduction in any medium, provided you give appropriate credit to the original author(s) and the source, provide a link to the Creative Commons license, and indicate if changes were made. 